\title{
STUDI STABILITAS PEMASANGAN PSS DENGAN MEMANFAATKAN SINYAL GLOBAL BERBASIS PSO PADA SISTEM TENAGA MULTIMESIN
}

\author{
Fajar Prasetia*, Sasongko Pramono Hadi dan Sarjiya \\ Departemen Teknik Elektro dan Teknologi Informasi Universitas Gadjah Mada \\ *Corresponding author, e-mail: fajar_prasetia@mail.ugm.ac.id
}

\begin{abstract}
Abstrak-Paper ini menyajikan studi stabilitas pada sistem tenaga multimesin yang dilengkapi dengan PSS berbasis sinyal global sebagai sinyal kendali. Filter dalam struktur PSS dirancang berdasarkan tanggapan frekuensinya, sedangkan parameter lead-lag dioptimisasi dengan PSO. Unjuk kerja dari rancangan ini diuji pada test system 3-Mesin 4-Bus yang diganggu dengan kenaikan beban. Hasil analisis eigenvalue, participation factor dan simulasi domain waktu menunjukkan bahwa sistem dengan PSS berbasis koordinasi antara sinyal lokal dan sinyal global memiliki unjuk kerja berupa rasio redaman, settling time dan overshoot yang lebih baik dari PSS berbasis sinyal lokal saja.
\end{abstract}

Kata Kunci : Multimesin, PSS, sinyal global, PSO, analisis eigenvalue, participation factor, stabilitas.

\begin{abstract}
This paper presents stability a study on multi-machine power system is equipped with PSS based on global signal as a control signal. Filters in PSS structure is designed based on frequency response, whereas the lead-lag parameters optimized by PSO. The performance of design proposed tested on 3Machine 4-Bus power system that disturb with load increasing. The eigenvalue and participation factor analysis results show that system with PSS based on coordination between local and global signal have a performance such us damping ratio, settling time and overshoot are better than system with PSS based on local signal only.
\end{abstract}

Keywords : Multi-machine, PSS, global signal, PSO, eigenvalue analysis, participation factor, stability.

\section{PENDAhuluan}

Koordinasi antara sinyal lokal dengan sinyal global mampu secara efektif meredam Low Frequency Oscillations (LFO) [1-2]. Sinyal global yang dimaksud adalah sinyal kecepatan rotor yang berasal dari berbagai generator dalam suatu sistem interkoneksi. Sinyal-sinyal ini memungkinkan dikirim dari berbagai tempat yang jauh dan dikoordinasikan untuk dijadikan sinyal masukan PSS dengan Wide Area Measurement Systems (WAMS) seperti Phasor Measurement Unit (PMU) dan Supervisory Control and Data Acquisition (SCADA).

Studi terkait sinyal global selama ini hanya menggunakan High-Pass Filter (HPF) pada blok washout dari struktur ini meskipun efektif dalam meredam LFO [1-2] akan tetapi penggunaan Low-Pass Filter (LPF) dalam studi perancangan PSS berbasis sinyal global perlu diinvestigasi lebih lanjut.

Teknik komputasi heuristics untuk mengoptimisasi fungsi obyektif dengan menggunakan Fire Fly Algorithm (FFA) dipakai oleh [3], sedang Genetic Algorithm (GA) telah dipakai oleh [4-5]. Teknik komputasi GA dilaporkan akan mengalami penurunan unjuk kerja ketika diterapkan pada sistem yang memiliki fungsi obyektif epistatic yang tinggidimana parameter yang akan dioptimisasikan sangat terkorelasi sehingga mengakibatkan konvergensi yang prematur [6-7]. Teknik komputasi heuristics lain yaitu Particle Swarm Optimization (PSO) telah dipakai oleh [7-8]. PSO memiliki kelebihan dibandingkan dengan FFA dan GA yaitu memiliki konsep sederhana, mudah diimplementasikan dan komputasinya lebih efisien.

Perancangan PSS pada studi ini dilakukan untuk menginvestigasi pengaruh pemasangannya terhadap stabilitas sistem tenaga multimesin setelah terjadi gangguan. Teknik komputasi yang digunakan dalam perancangan parameter lead-lag adalah PSO, sedangkan perancangan filter didasarkan atas tanggapan frekuensinya. Metode yang diusulkan diuji keefektifan redaman terhadap osilasi pada test 
system melalui analisis modal dan simulasi domain waktu.

\section{METODOLOGI}

\subsection{Model Sistem Tenaga Multimesin}

Model Phillips-Heffron untuk sistem tenaga multimesin dapat diformulasikan sebagai berikut [9-11]:

$\dot{\Delta} \delta_{i}=\omega_{b i} \Delta \omega_{i}$

$\Delta \dot{\omega}_{l}=\frac{\mathbf{1}}{\mathbf{M}_{i}}\left(-\mathbf{K}_{1 \mathbf{i}} \Delta \delta_{i}-\mathbf{K}_{2 \mathbf{i}} \Delta \mathbf{E}_{\mathbf{q i}}^{\prime}\right)$

$\Delta \dot{\mathbf{E}}_{\mathbf{q} \mathbf{1}}^{\prime}=\frac{\mathbf{1}}{\mathbf{T}_{\mathbf{d} 0 \mathrm{i}}^{\prime}}\left(-\mathbf{K}_{4 \mathbf{i}} \Delta \delta_{i}+\Delta \mathbf{E}_{\mathbf{f d i}}\right)-\frac{1}{\mathbf{T}_{\mathbf{d} 0 \mathbf{i}}^{\prime} \mathbf{K}_{3 \mathbf{i}}} \Delta \mathbf{E}_{\mathbf{q i}}^{\prime}$

$\Delta \dot{\mathbf{E}}_{\mathrm{fdl}}^{\prime}=-\frac{\mathbf{K}_{\mathrm{Ai}}}{\mathbf{T}_{\mathrm{Ai}}}\left(\mathbf{K}_{\mathbf{5 i}} \Delta \delta_{i}+\mathbf{K}_{\mathbf{6 i}} \Delta \mathbf{E}_{\mathbf{q i}}^{\prime}\right)-\frac{\mathbf{1}}{\mathbf{T}_{\mathrm{Ai}}} \Delta \mathbf{E}_{\mathrm{fdi}}$

Persamaan (1)-(4) dibawa ke bentuk sistem matriks sebagai berikut:

$\left[\begin{array}{c}\Delta \dot{\delta}_{\imath} \\ \Delta \dot{\omega}_{l} \\ \Delta \dot{\mathbf{E}}_{\mathbf{q} \mathbf{1}}^{\prime} \\ \Delta \dot{\mathbf{E}}_{\mathbf{f d} \mathbf{l}}^{\prime}\end{array}\right]=\left[\begin{array}{cccc}0 & \omega_{b i} & 0 & 0 \\ -\frac{\mathbf{K}_{\mathbf{1 i}}}{\mathbf{M}_{\mathbf{i}}} & 0 & -\frac{\mathbf{K}_{\mathbf{2 i}}}{\mathbf{M}_{\mathbf{i}}} & 0 \\ -\frac{\mathbf{K}_{4 \mathbf{i}}}{\mathbf{T}_{\mathbf{d 0 i}}^{\prime}} & 0 & -\frac{\mathbf{1}}{\mathbf{T}_{\mathbf{d} 0 \mathbf{i}}^{\prime} \mathbf{K}_{\mathbf{3 i}}} & \mathbf{1} \\ -\frac{\mathbf{K}_{\mathbf{A i}} \mathbf{K}_{\mathbf{5 i}}^{\prime}}{\mathbf{T}_{\mathbf{A i} \mathbf{i}}} & 0 & -\frac{\mathbf{K}_{\mathbf{A i}} \mathbf{K}_{\mathbf{6 i}}}{\mathbf{T}_{\mathbf{A i}}}-\frac{\mathbf{1}}{\mathbf{T}_{\mathbf{A i}}}\end{array}\right]\left[\begin{array}{c}\Delta \delta_{i} \\ \Delta \omega_{i} \\ \Delta \mathbf{E}_{\mathbf{q i}}^{\prime} \\ \Delta \mathbf{E}_{\mathbf{f d i}}\end{array}\right]$

dimana variabel dan parameter sistem pada persamaan (1)-(5) dinyatakan dalam vektor atau matriks dimensi n, sebagai contohnya:

$\Delta \delta=\left[\begin{array}{lllll}\Delta \delta_{1} & \Delta \delta_{2} & \Delta \delta_{3} & \ldots & \Delta \delta_{n}\end{array}\right]^{T}$

Konstanta $\mathbf{K}_{\mathbf{1 i}}, \mathbf{K}_{\mathbf{2 i}}, \mathbf{K}_{\mathbf{3 i}}, \mathbf{K}_{\mathbf{4 i}}, \mathbf{K}_{\mathbf{5 i}}$ dan $\mathbf{K}_{\mathbf{6 i}}$ dinamakan konstanta Phillips-Heffron.

\subsection{Model PSS}

Rancangan pengendali pada studi ini terdiri dari dua cabang Lead-Lag PSS seperti pada Gambar 1 yaitu cabang pertama untuk LFO Lokal dan cabang kedua untuk LFO Inter-area. Kedua cabang secara umum memiliki struktur gain, washout filter, dan kompensator lead-lag. Gain $G, K_{L}$, dan $K_{I}$ dipilih untuk menyediakan redaman yang memadai baik dari modus lokal maupun inter-area. Ada dua jenis washout filter, pertama berupa High Pass Filter (HPF) yang memuat $T_{W}$ dan lainnya berupa Low Pass Filter (LPF) yang memuat $T_{v}$ keduanya dapat mengurangi bias steady state pada keluaran PSS, sehingga PSS hanya akan menanggapi osilasi pada kecepatan rotor. Kompensator lead-lag yang memuat konstanta waktu $T_{1}-T_{4}$ dan $\tau_{1}-$ $\tau_{4}$ menyediakan phase lead bagi masukan sinyal PSS dengan range frekuensi sekitar 0.1-3 Hz.

Cabang pertama memiliki sinyal masukan perubahan kecepatan rotor generator lokal $\Delta \omega_{i}$ yang selanjutnya dinamakan sinyal lokal $\Delta \omega_{i}$. Fungsi alih dari cabang pertama yaitu:

$H_{P S S 1 i(S)}$

$=G K_{L}\left[\frac{s T_{W}}{1+s T_{W}}\right]\left[\frac{1+s T_{1}}{1+s T_{2}}\right]\left[\frac{1+s T_{3}}{1+s T_{4}}\right]$

Cabang kedua memiliki sinyal masukan selisih perubahan kecepatan rotor generator lokal $\Delta \omega_{i}$ dengan perubahan kecepatan rotor generator tetangga di area yang berbeda yang selanjutnya dinamakan sinyal global $\Delta \omega_{i j}$. Fungsi alih dari cabang kedua yaitu:

$H_{P S S 2 i(S)}$
$=G K_{I}\left[\frac{s T_{W}}{1+s T_{W}}\right]\left[\frac{s T_{V}}{1+s T_{V}}\right]\left[\frac{1+s \tau_{1}}{1+s \tau_{2}}\right]\left[\frac{1+s \tau_{3}}{1+s \tau_{4}}\right]$

Sinyal kendali total $V_{S T}$ didapat dari persamaan berikut:

$V_{S T}=\left(H_{P S S 1 i} * \Delta \omega_{i}\right)+\left(H_{P S S 2 i} * \Delta \omega_{i j}\right)$

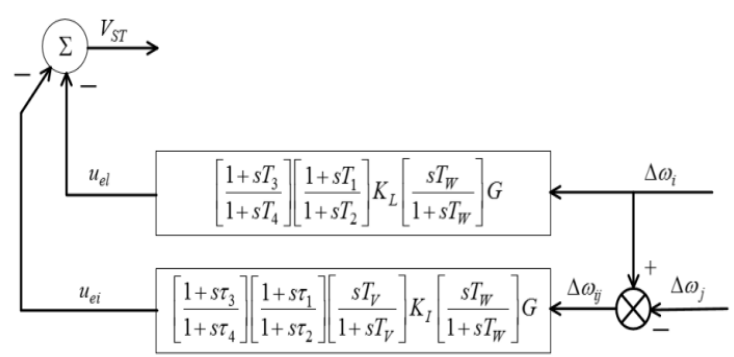

Gambar 1. Blok diagram model PSS dalam studi

Nilai parameter $G, K_{L}$, dan $K_{I}=0.1-50$; $T_{1}, T_{3}, \tau_{1}$, dan $\tau_{3}=0.2-1.5 \mathrm{dtk} ; T_{2}, T_{4}, \tau_{2}$, dan $\tau_{4}=0.02-0.15 \mathrm{dtk} ; T_{W}=10 \mathrm{dtk}$ [12]; $T_{v}=\left(\alpha_{L P F}\right)^{-1}$, dimana besarnya nilai cut off $\alpha_{L P F} 0.2$ kali dari nilai frekuensi osilasi saat sistem dikenakan gangguan $f_{d}$ [13].

\subsection{Teknik Optimisasi PSO}

Parameter $G, K_{L}, K_{I}, T_{1}-T_{4}$, dan $\tau_{1-} \tau_{4}$ dioptimisasi untuk meminimalkan fungsi obyektif berikut agar diperoleh kendali yang optimal [8]: 
- Fungsi obyektif untuk menempatkan komponen real eigenvalue $\sigma$ di sebelah kiri sumbu imajiner, yaitu:

$\mathbf{J}_{\mathbf{1}}=\sum_{\sigma_{i} \geq \sigma_{0}}\left(\sigma_{0}-\sigma_{i}\right)^{2}$

dimana, $\sigma_{i}$ adalah bagian real eigen value ke-i, sedangkan $\sigma_{0}$ adalah threshold yang dipilih. Nilai real eigenvalue yang diharapkan berada pada $\sigma_{\mathrm{i}} \leq \sigma_{0}$ sebagaimana Gambar 2 berikut:

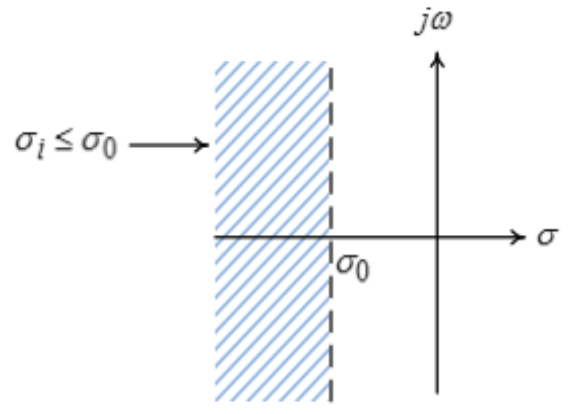

Gambar 2. Area lokasi eigenvalue untuk fungsi obyektif $J_{1}$

- Fungsi obyektif untuk membatasi overshoot maksimum, yaitu:

$\mathbf{J}_{2}=\sum_{\zeta_{i} \geq \zeta_{0}}\left(\zeta_{0}-\zeta_{i}\right)^{2}$

dimana, $\zeta_{i}$ adalah rasio peredaman dari eigenvalue ke-i. Nilai rasio redaman yang diharapkan berada pada $\zeta_{i} \geq \zeta_{0}$ sebagaimana Gambar 3 berikut:

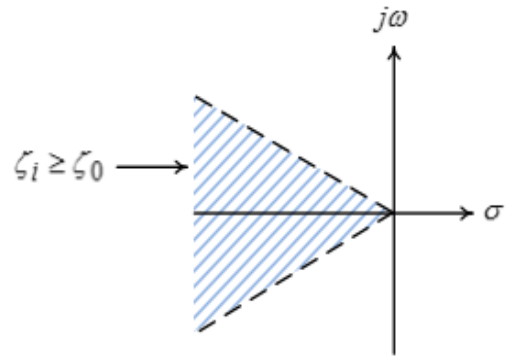

Gambar 3. Area lokasi eigenvalue untuk fungsi obyektif $\mathrm{J}_{2}$

Permasalahan optimisasi dengan dua fungsi obyektif diformulasikan sebagai berikut:
Minimalkan $\mathbf{J}_{\mathbf{1}}$ dan $\mathbf{J}_{\mathbf{2}}$

tunduk kepada

$G^{\min } \leq G \leq G^{\max }$

$K_{L}^{\text {min }} \leq K_{L} \leq K_{L}^{\text {max }}$

$K_{I}^{\min } \leq K_{I} \leq K_{I}^{\max }$

$T_{1}^{\min } \leq T_{1} \leq T_{1}^{\max }, \tau_{1}^{\min } \leq \tau_{1} \leq \tau_{1}^{\max }$

$T_{2}^{\min } \leq T_{2} \leq T_{2}^{\max }, \tau_{2}^{\min } \leq \tau_{2} \leq \tau_{2}^{\max }$

$T_{3}^{\text {min }} \leq T_{3} \leq T_{3}^{\text {max }}, \tau_{3}^{\text {min }} \leq \tau_{3} \leq \tau_{3}^{\max }$

$T_{4}^{\min } \leq T_{4} \leq T_{4}^{\max }, \tau_{4}^{\min } \leq \tau_{4} \leq \tau_{4}^{\max }$

Parameter threshold $\sigma_{0}$ dipilih -0.3 dan $\zeta_{0}$ dipilih 0.2. Teknik komputasi PSO diterapkan untuk menyelesaikan permasalahan optimisasi persamaan (11). Konfigurasi komputasi PSO ditentukan: jumlah populasi 100 , jumlah iterasi maksimum 100 dan initial inertia weight 0.9 0.4 .

\section{HASIL DAN PEMBAHASAN}

\subsection{Model Sistem Tenaga Multimesin Dengan PSS Sinyal Global}

Sistem tenaga 3-Mesin 4-Bus seperti yang ditunjukkan pada Gambar 4 digunakan sebagai test system pada studi ini. Parameter test system telah dimodifikasi dari [14] dan disajikan pada Lampiran.

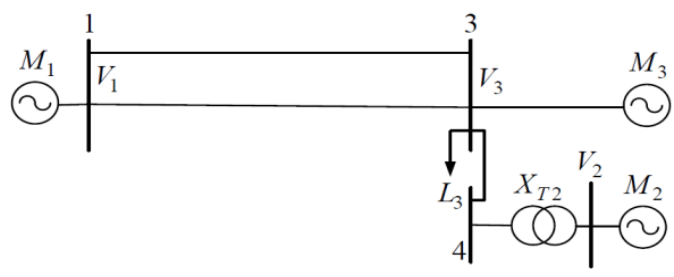

Gambar 4. Test System 3-Mesin 4-Bus

Konfigurasi PSS dalam sistem test system ditunjukkan pada blok diagram Gambar 5, dimana PSS berbasis sinyal lokal dan sinyal global dipasang di mesin 1, sedangkan PSS berbasis sinyal lokal dipasang di mesin 2 dan 3 . Sinyal global dalam studi ini adalah selisih perubahan kecepatan rotor generator $1 \Delta \omega_{1}$ dengan perubahan kecepatan rotor generator 2 $\Delta \omega_{2}$. Tiap mesin dideskripsikan oleh persamaan (5), sehingga persamaan dinamis dari konfigurasi ini adalah sebagai berikut:

$\dot{\mathbf{x}}=\mathbf{A}_{\mathbf{C}} \mathbf{X}$

$\left[\begin{array}{c}\dot{\mathbf{X}}_{1} \\ \dot{\mathbf{x}}_{2} \\ \dot{\mathbf{x}}_{3}\end{array}\right]=\left[\begin{array}{lll}\mathbf{A}_{11} & \mathbf{A}_{12} & \mathbf{A}_{13} \\ \mathbf{A}_{21} & \mathbf{A}_{22} & \mathbf{A}_{23} \\ \mathbf{A}_{31} & \mathbf{A}_{32} & \mathbf{A}_{33}\end{array}\right]\left[\begin{array}{l}\mathbf{X}_{1} \\ \mathbf{X}_{2} \\ \mathbf{X}_{3}\end{array}\right]$ 
dengan,

$\mathbf{x}_{\mathbf{1}}=\left[\begin{array}{llll}\Delta \delta_{1} & \Delta \omega_{1} & \Delta \mathbf{E}_{\mathbf{q} 1}^{\prime} & \Delta \mathbf{E}_{\mathbf{f d} 1}^{\prime}\end{array}\right.$ $\left.\begin{array}{lllllll}x_{11} & x_{21} & u_{e l 1} & x_{31} & x_{41} & x_{51} & u_{e I 1}\end{array}\right]^{T}$

$\mathbf{x}_{2}=\left[\begin{array}{lllllll}\Delta \delta_{2} & \Delta \omega_{2} & \Delta \mathbf{E}_{\mathbf{q} 2}^{\prime} & \Delta \mathbf{E}_{\mathbf{f d} 2}^{\prime} & x_{12} & x_{22} & u_{e l 2}\end{array}\right]^{T}$

$\mathbf{x}_{\mathbf{3}}=\left[\begin{array}{lllllll}\Delta \delta_{3} & \Delta \omega_{3} & \Delta \mathbf{E}_{\mathbf{q} 3}^{\prime} & \Delta \mathbf{E}_{\mathbf{f d} 3}^{\prime} & x_{13} & x_{23} & u_{e l 3}\end{array}\right]^{T}$

Matriks gabungan $\mathbf{A}_{\boldsymbol{C}}$ berdimensi $(25,25)$, yang terdiri dari $\mathbf{A}_{\mathbf{1 1}}, \mathbf{A}_{\mathbf{2 2}}$ dan $\mathbf{A}_{\mathbf{3 3}}$ adalah matriks sistem lokal; $\mathbf{A}_{\mathbf{1 2}}, \mathbf{A}_{\mathbf{1 3}}, \mathbf{A}_{\mathbf{2 1}}, \mathbf{A}_{\mathbf{2 3}}, \mathbf{\mathbf { A } _ { \mathbf { 2 } }}, \mathbf{\mathbf { A } _ { \mathbf { 3 1 } }}$ dan $\mathbf{A}_{32}$ terkait dengan interaksi dinamis diantara mesin.

\subsection{Hasil Analisis Modal dan Domain Waktu}

Investigasi pengaruh pemasangan PSS sinyal global terhadap stabilitas sistem setelah sistem diganggu berupa kenaikan daya $0.1 \mathrm{pu}$ dilakukan dengan analisis modal (eigenvalue dan participation factor) dan tanggapan simulasi domain waktu pada tiga skenario model dan simulasi untuk dibandingkan yaitu:

1. Sistem Tanpa kendali

2. Sistem Dengan PSS Sinyal Lokal

3. Sistem Dengan PSS Sinyal Global

Parameter-parameter pada skenario ke-2 dan ke-3 dioptimisasi dengan PSO untuk membandingkan pengaruh penambahan sinyal global.

\subsubsection{Sistem Tanpa Kendali}

Berdasarkan hasil analisis modal pada Tabel 1, fenomena LFO muncul di ketiga mesin pada skenario ini. Mesin 1 memiliki rasio redaman $\zeta$ sebesar 0.0012 , mesin 2 sebesar 0.0585 dan mesin 3 sebesar 0.0012. Rasio redaman dari masing-masing mesin ini masih terlalu redah sehingga dibutuhkan pengendali untuk menaikkan redaman terhadap LFO.

Hasil simulasi domain waktu ditunjukkan pada Gambar 6, dimana tanggapan perubahan sudut rotor terhadap waktu memiliki overshoot sebesar $31.99 \%$ dan settling time 11.57 detik, sedangkan tanggapan perubahan kecepatan rotor terhadap waktu memiliki settling time 12.73 detik.

\subsubsection{Sistem Dengan PSS Sinyal Lokal}

Hasil perancangan PSS pada skenario ini dengan PSO ditunjukkan pada Tabel 2. Penambahan PSS dengan memanfaatkan sinyal perubahan kecepatan rotor generator lokal pada masing-masing mesin, secara umum menaikkan rasio redaman dari LFO yang muncul seperti yang terlihat pada Tabel 1 dimana mesin 1 memiliki rasio redaman $\zeta$ sebesar 0.179 , mesin 2 sebesar 0.086 dan mesin 3 sebesar 0.061 .

Hasil ini sesuai dengan hasil simulasinya seperti yang ditunjukkan pada Gambar 7, dimana penambahan PSS ini mengakibatkan overshoot menurun $13.07 \%$ dan mempercepat settling time 7.54 detik untuk tanggapan perubahan sudut rotor, sedangkan untuk tanggapan perubahan kecepatan rotor mempercepat settling time sebesar 8.32 detik.

Tabel 1. Hasil analisis eigenvalue dan participation factor untuk ketiga skenario

\begin{tabular}{|c|c|c|c|c|c|c|c|c|}
\hline \multicolumn{3}{|c|}{ Tanpa Kendali } & \multicolumn{3}{|c|}{ Dengan PSS SinyalLokal } & \multicolumn{3}{|c|}{ Dengan PSS Sinyal Global } \\
\hline Eigenvalues & $\begin{array}{c}\text { State } \\
\text { Dominan }\end{array}$ & $\zeta(\mathrm{pu})$ & Eigenvalues & $\begin{array}{c}\text { State } \\
\text { Dominan }\end{array}$ & $\zeta(\mathrm{pu})$ & Eigenvalues & $\begin{array}{c}\text { State } \\
\text { Dominan }\end{array}$ & $\zeta(\mathrm{pu})$ \\
\hline-97.0715 & $\Delta E_{f d 1}$ & 1 & -97.5771 & $\Delta E_{f d 3}$ & 1 & -98.4975 & $\Delta E_{f d 1}$ & 1 \\
\hline-97.3471 & $\Delta E_{f d 3}$ & 1 & -97.4065 & $\Delta E_{f d 1}$ & 1 & -97.5464 & $\Delta E_{f d 3}$ & 1 \\
\hline$-0.3839 \pm 6.5464 i$ & $\Delta \delta_{2}, \Delta \omega_{2}$ & 0.0585 & -19.5243 & $x_{2 l 2}$ & 1 & -34.1336 & $u_{e l 2}$ & 1 \\
\hline$-0.1508 \pm 4.6899 i$ & $\Delta \delta_{1}, \Delta \omega_{1}$ & 0.0321 & $-9.0703 \pm 4.2235 i$ & $u_{e l 3}$ & 0.907 & -18.6328 & $x_{2 l 2}$ & 1 \\
\hline$-0.0033 \pm 2.7854 \mathrm{i}$ & $\Delta \delta_{3}, \Delta \omega_{3}$ & 0.0012 & $-6.6347 \pm 4.6953 i$ & $u_{e l 1}$ & 0.816 & -17.303 & $x_{2 l 3}$ & 1 \\
\hline$-2.4266 \pm 2.3942 i$ & $\Delta E_{q 2}^{\prime}$ & 0.7118 & $-0.5626 \pm 6.5032 i$ & $\Delta \delta_{2}, \Delta \omega_{2}$ & 0.086 & $-7.3952 \pm 10.2236 \mathrm{i}$ & $\Delta E_{q 1}^{\prime}$ & 0.5861 \\
\hline-2.3574 & $\Delta E_{q 1}^{\prime}$ & 1 & -6.6613 & $u_{e l 2}$ & 1 & -11.3511 & $u_{e l 3}$ & 1 \\
\hline \multirow[t]{11}{*}{-2.6781} & $\Delta E_{q 1}^{\prime}$ & 1 & $-0.8318 \pm 4.5615 i$ & $\Delta \delta_{1}, \Delta \omega_{1}$ & 0.179 & $-1.0312 \pm 6.3584 i$ & $\Delta \delta_{2}, \Delta \omega_{2}$ & 0.1601 \\
\hline & & & $-0.1607 \pm 2.6085 i$ & $\Delta \delta_{3}, \Delta \omega_{3}$ & 0.061 & $-8.3230 \pm 0.1485 i$ & $x_{3 i 1}$ & 0.9998 \\
\hline & & & $-2.4472 \pm 2.2685 i$ & $\Delta E_{q 2}^{\prime}$ & 0.733 & $-1.2707 \pm 4.0403 i$ & $\Delta \delta_{1}, \Delta \omega_{1}$ & 0.3000 \\
\hline & & & -2.6747 & $\Delta E_{q 1}^{\prime}$ & 1 & $-0.3088 \pm 2.6804 i$ & $\Delta \delta_{3}, \Delta \omega_{3}$ & 0.1144 \\
\hline & & & -2.3638 & $\Delta E_{q 3}^{\prime}$ & 1 & $-2.0523 \pm 1.8360 \mathrm{i}$ & $\Delta E_{q 2}^{\prime}$ & 0.7453 \\
\hline & & & -0.2336 & $x_{1 l 1}$ & 1 & -2.7892 & $\Delta E_{q 1}^{\prime}$ & 1 \\
\hline & & & -0.1111 & $x_{1 l 3}$ & 1 & -2.4021 & $\Delta E_{q 3}^{\prime}$ & 1 \\
\hline & & & -0.0007 & $x_{112}$ & 1 & -0.3535 & $x_{112}$ & 1 \\
\hline & & & & & & -0.1 & $x_{1 l 1}$ & 1 \\
\hline & & & & & & -0.1039 & $x_{1 l 3}$ & 1 \\
\hline & & & & & & $-0.0062 \pm 0.0039 i$ & $x_{1 i 1}$ & 0.8465 \\
\hline
\end{tabular}




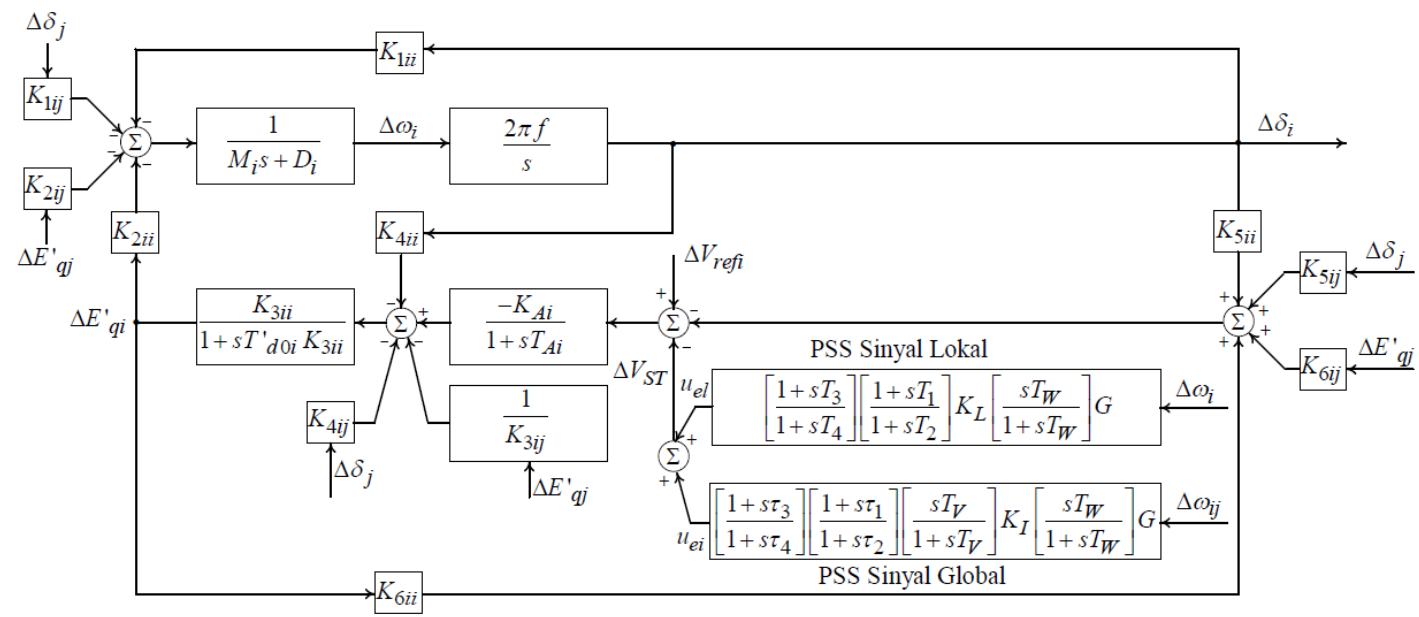

Gambar 5. Model Phillips-Heffron dengan PSS sinyal lokal dan global terpasang
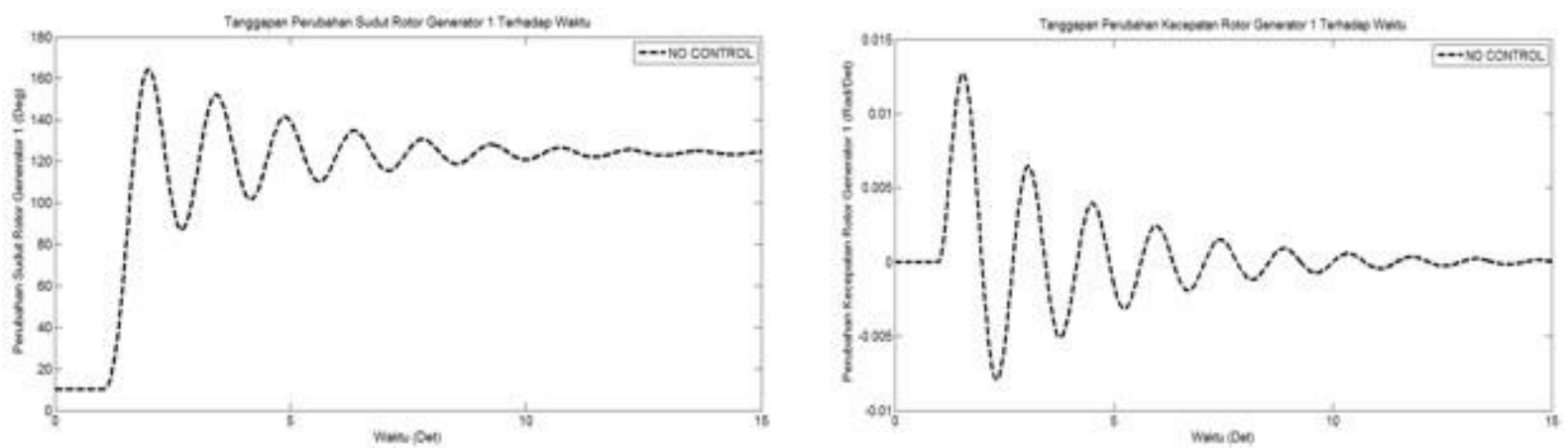

Gambar 6. Hasil simulasi domain waktu sistem tanpa pengendali
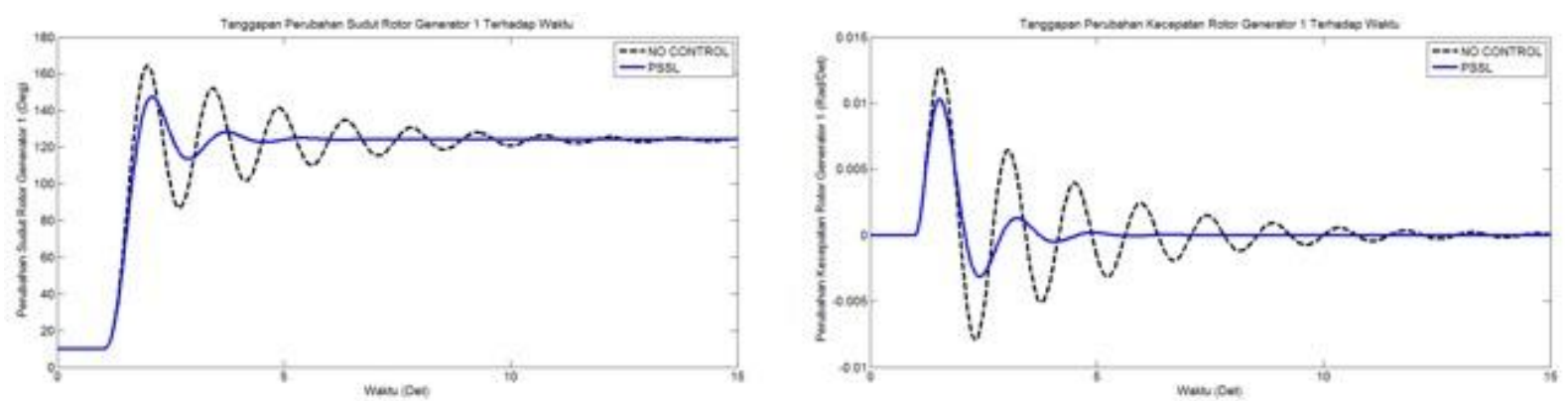

Gambar 7. Hasil simulasi domain waktu sistem dengan PSS sinyal lokal
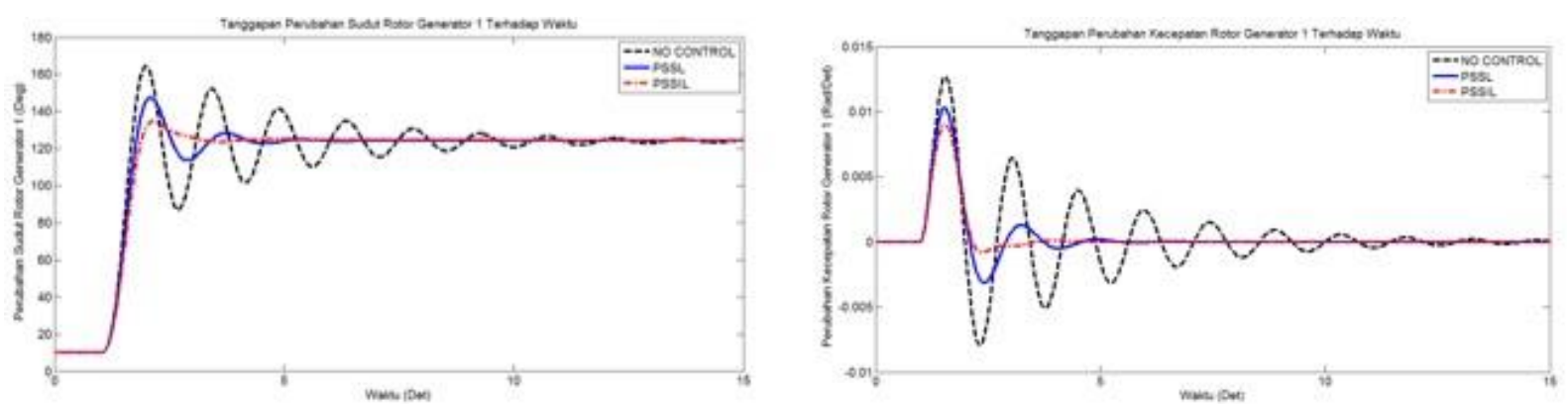

Gambar 8. Hasil simulasi domain waktu sistem dengan PSS sinyal global 
Tabel 2. Hasil optimisasi parameter PSS sinyal lokal

\begin{tabular}{cccccc}
\hline $\begin{array}{c}\text { Param } \\
\text { PSSLG1 }\end{array}$ & Nilai & $\begin{array}{c}\text { Param } \\
\text { PSSLG2 }\end{array}$ & Nilai & $\begin{array}{c}\text { Param } \\
\text { PSSLG3 }\end{array}$ & Nilai \\
\hline $\mathbf{G}_{\mathbf{L 1}}$ & 4.3309 & $\mathbf{G}_{\mathbf{L} 2}$ & 0.4818 & $\mathbf{G}_{\mathbf{L 3}}$ & 1.0742 \\
\hline $\mathbf{K}_{\mathbf{L 1}}$ & 1.7602 & $\mathbf{K}_{\mathbf{L} 2}$ & 1.1005 & $\mathbf{K}_{\mathbf{L 3}}$ & 1.2877 \\
\hline $\mathbf{T}_{\text {1PSSL1 }}$ & 0.3339 & $\mathbf{T}_{\text {1PSSL2 }}$ & 0.3293 & $\mathbf{T}_{\text {1PSSL3 }}$ & 1.1926 \\
\hline $\mathbf{T}_{\text {2PSSL1 }}$ & 0.1157 & $\mathbf{T}_{\text {2PSSL2 }}$ & 0.0517 & $\mathbf{T}_{\text {2PSSL3 }}$ & 0.1007 \\
\hline $\mathbf{T}_{\text {3PSSL1 }}$ & 0.7781 & $\mathbf{T}_{\text {3PSSL2 }}$ & 0.8448 & $\mathbf{T}_{\text {3PSSL3 }}$ & 0.5011 \\
\hline $\mathbf{T}_{\text {4PSSL1 }}$ & 0.1496 & $\mathbf{T}_{\text {4PSSL2 }}$ & 0.1450 & $\mathbf{T}_{\text {4PSSL3 }}$ & 0.1138 \\
\hline
\end{tabular}

\subsubsection{Sistem Dengan PSS Sinyal Global}

Hasil perancangan PSS dengan sinyal global dengan teknik komputasi PSO ditunjukkan pada Tabel 3. Parameter $T_{w}$ ditetapkan untuk PSS di tiap-tiap mesin sebesar 10 detik [11]. Frekuensi $f_{d 1}$ sebesar $0.7499 \mathrm{~Hz}$ didapatkan saat test system dikenakan gangguan berupa kenaikan daya sebesar $0.1 \mathrm{pu}$, sehingga $T_{V 1}$ bernilai 6.67 detik.

Hasil analisis modal sistem dengan pengendali PSS sinyal global ditunjukkan dengan Tabel 1. Rasio redaman dari mesin 1 mengalami kenaikan yang cukup signifikan jika dibandingkan dengan sistem dengan PSS sinyal lokal karena adanya sinyal global sebagai sinyal kendali. Kenaikan ini diiukuti naiknya rasio redaman dari dua mesin yang lain.

Tabel 3. Hasil optimisasi parameter PSS sinyal lokal dan global

\begin{tabular}{cccccccc}
\hline $\begin{array}{c}\text { Param } \\
\text { PSSLG1 }\end{array}$ & Nilai & $\begin{array}{c}\text { Param } \\
\text { PSSILG1 }\end{array}$ & Nilai & $\begin{array}{c}\text { Param } \\
\text { PSSLG2 }\end{array}$ & Nilai & $\begin{array}{c}\text { Param } \\
\text { PSSLG3 }\end{array}$ & Nilai \\
\hline $\mathbf{G}_{\mathrm{L} 1}$ & 7.2176 & $\mathbf{G}_{\mathrm{I1}}$ & 1.5048 & $\mathbf{G}_{\mathrm{L} 2}$ & 0.5563 & $\mathbf{G}_{\mathrm{L3}}$ & 0.6935 \\
\hline $\mathbf{K}_{\mathrm{L1}}$ & 2.6085 & $\mathbf{K}_{\mathrm{I1}}$ & 6.1953 & $\mathbf{K}_{\mathrm{L} 2}$ & 0.6564 & $\mathbf{K}_{\mathrm{L} 3}$ & 0.8876 \\
\hline $\mathbf{T}_{\mathbf{1 P S S L} 1}$ & 0.3242 & $\mathbf{T}_{1 \text { PSSI1 }}$ & 0.3606 & $\mathbf{T}_{1 \text { PSSL2 }}$ & 1.3690 & $\mathbf{T}_{1 \text { PSSL3 }}$ & 0.3792 \\
\hline $\mathbf{T}_{\text {2PSSL1 }}$ & 0.1404 & $\mathbf{T}_{\text {2PSSI1 }}$ & 0.1303 & $\mathbf{T}_{\text {2PSSL2 }}$ & 0.0465 & $\mathbf{T}_{\text {2PSSL3 }}$ & 0.0513 \\
\hline $\mathbf{T}_{\text {3PSSL1 }}$ & 0.6471 & $\mathbf{T}_{\text {3PSSI1 }}$ & 0.7945 & $\mathbf{T}_{\text {3PSSL2 }}$ & 0.8470 & $\mathbf{T}_{\text {3PSSL3 }}$ & 1.3945 \\
\hline $\mathbf{T}_{\text {4PSSL1 }}$ & 0.1494 & $\mathbf{T}_{\text {4PSSI1 }}$ & 0.0732 & $\mathbf{T}_{\text {4PSSL2 }}$ & 0.0309 & $\mathbf{T}_{4 \text { PSSL3 }}$ & 0.1048 \\
\hline
\end{tabular}

Hasil simulasi domain waktu ditunjukkan pada Gambar 8. Berdasarkan hasil ini, pengaruh pemasangan pengendali PSS dengan memanfaatkan sinyal lokal dan sinyal global secara bersamaan jika dibandingkan dengan pemasangan pengendali PSS dengan hanya memanfaatkan sinyal lokal saja pada test system di generator 1 yaitu dapat mempercepat settling time 1.12 detik dan menurunkan overshoot $10.42 \%$ pada tanggapan perubahan sudut rotor terhadap waktu, sedangkan pada tanggapan perubahan kecepatan rotor dapat mempercepat settling time sebesar 1.07 detik.

\section{KESIMPULAN}

Pemasangan pengendali PSS pada sistem tenaga multimesin dengan memanfaatkan dua sinyal kendali berupa sinyal lokal dan global memiliki unjuk kerja pengendalian yang lebih baik daripada PSS yang hanya memanfaatkan sinyal lokal saja. Hal ini ditunjukkan dengan skenario sistem dengan PSS sinyal global memiliki nilai rasio redaman tertinggi, settling time tercepat dan overshoot yang terendah dari dua skenario lainnya.

\section{DAFTAR PUSTAKA}

[1] Aboul-Ela ME, Fouad A A, McCalley JD, Sallam AA. Damping controller design for power system oscillations using global signals. IEEE Trans. on Power Systems. 1996; 11(2): 767-773.

[2] Mohammad MMP. Sinyal Global Untuk Kendali Optimal Berbasis NatureInspired Metaheuristic Algorithm Pada Sistem Multi Mesin Dengan GUPFC. M.Eng Thesis. Yogyakarta, Indonesia: Universitas Gadjah Mada; 2015.

[3] Adi K. Optimalisasi PID Power System Stabilizer Menggunakan Fire Fly Algorithm Pada Sistem Pembangkit Listrik Jawa-Bali. Jurnal Nasional Teknik Elektro. 2015; 4(1): 56-62.

[4] Abdel-Magid YL, Abido MA. Optimal Multi-objective Design of Robust Power System Stabilizers Using Genetic Algorithms. IEEE Trans on Power Systems. 2003; 18(3): 1125-1132.

[5] Sasongko PH. Dynamic Modeling and Damping Function of GUPFC in Multimachine Power System. IPTEK, The Journal for Technology and Science. 2011; 22 (4): 205-213.

[6] David BF. Evolutionary Computation Toward a New Philosophy of Machine Intelligence. New York: IEEE Press. 1995.

[7] Abido MA. Particle Swarm Optimization for Multi-Machine Power System Stabilizer Design. Proceedings of IEEE 
PES Summer Meeting. Vancouver, BC. 2001; 3: 1346-1351.

[8] Jalilvand A, Safari A, Aghmasheh R. Design of State Feedback Stabilizer for Multi-Machine Power System Using PSO Algorithm. Proc. Of the 12th IEEE Intrnal Multi-topic Conf. Karachi. 2008; 17-33.

[9] Yao-nan Y. Electric Power System Dynamics. New York: Academic Press. 1983.

[10] Yao-nan Y and Moussa HAM. Optimal Stabilization of A Multi-Machine System. in The IEEE Summer Meeting and International Symposium on High Power Testing. Portland, Ore. 1971; PAS-91(3): 18-23.

[11] Yao-nan Y, El-Sharkawi MA. Estimation of External Dynamic Equivalents of a Thirteen-Machine System. IEEE Trans. Power App. Syst. 1981; PAS-100(3): 1324-1332.

[12] Sauer PW, Pai MA. Power System Dynamics and Stability. New Jersey: Prentice Hall, Inc. 1998: 270-272.

[13] Andrea AZ. Power System Stabilizers for The Synchronous Generator Tuning and Performance Evaluation. M.Sc Thesis. Göteborg, Sweden: Chalmers University of Technology; 2013.

[14] Wang HF. Application of Modelling UPFC into Multi-Machine Power Systems. IEE Proc Gener. Transm. Distrib. 1999; 146(3): 306-312.

\section{Biodata Penulis}

Fajar Prasetia adalah mahasiswa program pascasarjana Departemen Teknik Elektro dan Teknologi Informasi, Fakultas Teknik, Universitas Gadjah Mada, Yogyakarta, Indonesia. Dia lulus dari program sarjana pada tahun 2011 dari Departemen Teknik Fisika, Fakultas Teknik, Universitas Gadjah Mada, Yogyakarta, Indonesia. Dia menekuni penelitian di bidang stabilitas sistem tenaga dan softcomputing.

Sasongko Pramono Hadi adalah pengajar program pascasarjana Departemen Teknik Elektro dan Teknologi Informasi, Fakultas Teknik, Universitas Gadjah Mada, Yogyakarta, Indonesia. Dia lulus dari program sarjana pada tahun 1979 dari Departemen Teknik Elektro,
Fakultas Teknik, Universitas Gadjah Mada, Yogyakarta, Indonesia. Dia memperoleh gelar master dan Doktor pada tahun 1985 dan 1988 dari Departemen Teknik Elektro The Institute Nationale Polytechnique de Grenoble (INPG), Perancis. Dia menekuni penelitian di bidang operasi, stabilitas dan analisis sistem tenaga dan analisis mesin listrik.

Sarjiya adalah pengajar program pascasarjana Departemen Teknik Elektro dan Teknologi Informasi, Fakultas Teknik, Universitas Gadjah Mada, Yogyakarta, Indonesia. Dia lulus dari program sarjana dan master pada tahun 1998 dan 2001 dari Departemen Teknik Elektro, Fakultas Teknik, Universitas Gadjah Mada, Yogyakarta, Indonesia. Dia memperoleh gelar Doktor pada tahun 2008 dari Departemen Teknik Elektro, Chulalongkorn University, Thailand. Dia lulus dari program Postdoctoral, Departemen Teknik Elektro, The University of Tokyo, Jepang pada tahun 2008. Dia menekuni penelitian di bidang Kehandalan dan operasi ekonomis dan optimisasi dalam deregulasi sistem tenaga.

\section{LAMPIRAN}

Parameter-parameter dari test system 3-Mesin 4Bus (dalam pu kecuali jika diindikasikan)

\section{Generator:}

$$
\begin{aligned}
& \text { (I) } H_{1}=11.8 d t k ; \quad x_{d 1}=0.1675 \text {; } \\
& x_{d 1}^{\prime}=0.0392 ; \quad D_{1}=0 ; \\
& x_{q 1}=0.1675 ; \quad T_{d 01}^{\prime}=7,5 d t k ; \\
& \text { (II) } H_{2}=5.9 d t k ; \quad x_{d 2}=0.1675 \text {; } \\
& x_{d 2}^{\prime}=0.0392 ; \quad D_{2}=0 \text {; } \\
& x_{q 2}=0.1675 ; \quad T^{\prime}{ }_{d 02}=7,5 d t k ; \\
& \text { (III) } H_{3}=11.8 d t k ; \quad x_{d 3}=0.1715 \text {; } \\
& x_{d 3}^{\prime}=0.0208 ; \quad D_{3}=0 \text {; } \\
& x_{q 3}=0.1023 ; \quad T^{\prime}{ }_{d 03}=7,5 d t k
\end{aligned}
$$

Sistem Eksitasi:

$$
\begin{array}{ll}
K_{A 1}=20 ; & T_{A 1}=0.01 d t k ; \\
K_{A 2}=20 ; & T_{A 2}=0.2 d t k ; \\
K_{A 3}=20 ; & T_{A 3}=0.01 d t k
\end{array}
$$

Transformator:

$Z_{t 2}=\mathrm{j} 0.03$

Saluran Transmisi:

$$
\begin{array}{rlrl}
Z_{13} & =\mathrm{j} 1.2 ; & Z_{23} & =\mathrm{j} 0.3 ; \\
Z_{14} & =\mathrm{j} 0.4 ; & L_{3} & =1.5+j 0.5 \\
\text { Kondisi Operasi: } & & \\
\bar{V}_{1 t} & =1.0 \angle 9^{o} ; & \bar{V}_{2 t} & =1.0 \angle 5^{o} ; \\
\bar{V}_{3 t} & =1.0 \angle 0^{o} ; & P & =1.1 ; \\
Q & =0.15 ; & V_{t} & =1.032
\end{array}
$$

